\title{
Review
}

\section{Visualising insulin secretion. The Minkowski Lecture 2004}

\author{
G. A. Rutter ${ }^{1,2}$ \\ ${ }^{1}$ Henry Wellcome Laboratories for Integrated Cell Signalling, School of Medical Sciences, University of Bristol, Bristol, UK \\ ${ }^{2}$ Department of Biochemistry, School of Medical Sciences, University of Bristol, Bristol, UK
}

\begin{abstract}
Insulin secretion from pancreatic islet beta cells is a tightly regulated process, under the close control of blood glucose concentrations, neural inputs and circulating hormones. Defects in glucose-triggered insulin secretion, possibly exacerbated by a decrease in beta cell mass, are ultimately responsible for the development of type 2 diabetes. A full understanding of the mechanisms by which glucose and other nutrients trigger insulin secretion will probably be essential to allow for the development of new therapies of type 2 diabetes and for the derivation of "artificial" beta cells from embryonic stem cells as a treatment for type 1 diabetes. I focus here on recent developments in our understanding of beta cell glucose sensing, achieved in part through the development of recombinant targeted probes (luciferase, green fluorescent protein)
\end{abstract}

that allow islet beta cell metabolism and $\mathrm{Ca}^{2+}$ handling to be imaged in situ in the intact islet with single cell resolution. Combined with classical biochemistry, these techniques show that the beta cell is uniquely poised, thanks to the expression of low levels of lactate dehydrogenase and plasma membrane lactate/monocarboxylate transporters, to channel glucose carbons towards oxidative metabolism, ATP synthesis and inhibition of AMP-activated protein kinase, a newly defined regulator of insulin release. I also discuss the molecular basis of the recruitment of secretory vesicles to the cell surface, analysed by the use of new imaging techniques including total internal reflection of fluorescence, as well as the "nanomechanics" of the exocytotic event itself.

Keywords ATP $\cdot$ Beta cell $\cdot \mathrm{Ca}^{2+} \cdot$ Exocytosis $\cdot$ GFP . Imaging $\cdot$ Islet $\cdot$ Luciferase $\cdot$ Metabolism $\cdot$ Secretion
Received: 12 August 2004 / Accepted: 4 September 2004 Published online: 17 November 2004

C) Springer-Verlag 2004

\section{G. A. Rutter $(\bullet)$}

Henry Wellcome Laboratories for Integrated Cell Signalling, School of Medical Sciences, University of Bristol, Bristol, UK E-mail: g.a.rutter@bris.ac.uk

Tel.: +44-117-9546401, Fax: +44-117-9288274

Abbreviations: AMPK, AMP-activated protein kinase . EGFP, enhanced green fluorescent protein - GK, glucokinase $\mathrm{K}_{\text {ATP }}$, ATP-sensitive $\mathrm{K}^{+}$channel $\cdot \mathrm{LDH}$, lactate dehydrogenase $\cdot$ MCT-1, monocarboxylate transporter- $1 \cdot \mathrm{mRFP}$, monomeric red fluorescent protein - myoVa, myosin Va $\cdot$ NPY, neuropeptide Y $\cdot$ PC, pyruvate carboxylase $\cdot$ SREBP1c, sterol regulatory element binding protein- $1 \mathrm{c} \cdot \mathrm{TCA}$, tricarboxylate/ citrate cycle TIRF, total internal reflection of fluorescence microscopy $\cdot$ tPA, tissue plasminogen activator

\section{Introduction}

Tight regulation of insulin release is essential for normal blood glucose homeostasis. Were daily insulin release to exceed $\sim 2 \%$ of the total pancreatic content (more than 2500 units) then fatal hypoglycaemia would ensue. Conversely, whilst decreases in beta cell mass are apparent in late stage type 2 diabetes [1], defective insulin release from existing beta cells seems likely to be the underlying cause of this disease in most cases. Thus, hyperglycaemia is not usually evident before the loss of $\sim 70 \%$ of beta cell mass in type 1 diabetes [2], while 40 to $50 \%$ of the beta cell mass remains intact after baboons are rendered diabetic with streptozotocin [3].

The study of glucose-regulated insulin secretion began in earnest in the 1960 s with the establishment 
of a radioimmunoassay for insulin [4]. More recently, studies on individual beta cells were made possible with the development of electrophysiological approaches including amperometry [5] and measurements of membrane capacitance [6,7]. Though the latter techniques provide remarkable temporal resolution, they are, however, limited with respect to the spatial aspects of insulin release. Overcoming this limitation, molecular approaches now allow the expression in living beta cells and islets of a range of recombinant fluorescent and bioluminescent probes, often derived from lower organisms [8]. Combined with advances in imaging technologies, these tools enable the secretory event to be imaged in real time, allowing the intracellular signalling mechanisms that control it to be dissected.

\section{Glucose sensing: adenosine-triphosphate-sensitive $\mathrm{K}^{+}$channels}

Glucose causes efficient increases in total intracellular ATP content (or an increase in ATP : ADP ratio) [9], which are reflected by measurable and sometimes oscillatory increases in concentrations of free ATP [10, 11]. These changes can be imaged in living beta cells or islets using recombinant targeted luciferase, an ATP-dependent photoprotein derived from the North American firefly, Photinus pyralis, and photon-counting imaging (Fig. 1). The demonstration of ATPinhibitable $\mathrm{K}^{+}$currents in isolated beta cells [12] and their closure in intact cells by glucose [13] provided early evidence that such changes in free [ATP] may be critical for the response to glucose. A decade or so later, the channel-forming subunit (an inwardly rectifying $\mathrm{K}^{+}$channel, termed $\mathrm{K}_{\mathrm{ir}} 6.2$ ) of an ATP-sensitive $\mathrm{K}^{+}\left(\mathrm{K}_{\text {ATP }}\right)$ channel was cloned from a beta cell cDNA library by Seino and colleagues [14], whilst an associated transmembrane protein of the "ABC cassette family", SUR1, which is capable of binding the sulphonylurea class of oral hypoglycaemic agents, was cloned by AguilarBryan et al. [15].

Closure of $\mathrm{K}_{\text {АTP }}$ channels [16], and a progressive depolarisation of the plasma membrane (from a resting potential of about $-70 \mathrm{mV}$ to $0 \mathrm{mV}$ ) [17], cause the beta cell to fire action potentials as glucose concentrations increase. These, in turn, open voltage-sensitive, L-type $\mathrm{Ca}^{2+}$ channels [18], and prompt the influx of $\mathrm{Ca}^{2+}$ ions. The resulting increase in intracellular free $\mathrm{Ca}^{2+}$ concentration $[19,20]$ is then the major stimulus that triggers secretory vesicle fusion with the plasma membrane $[21,22]$, whilst $\mathrm{Ca}^{2+}$ uptake by mitochondria also enhances mitochondrial ATP synthesis [23] to sustain glucose signalling $[10,11]$. a
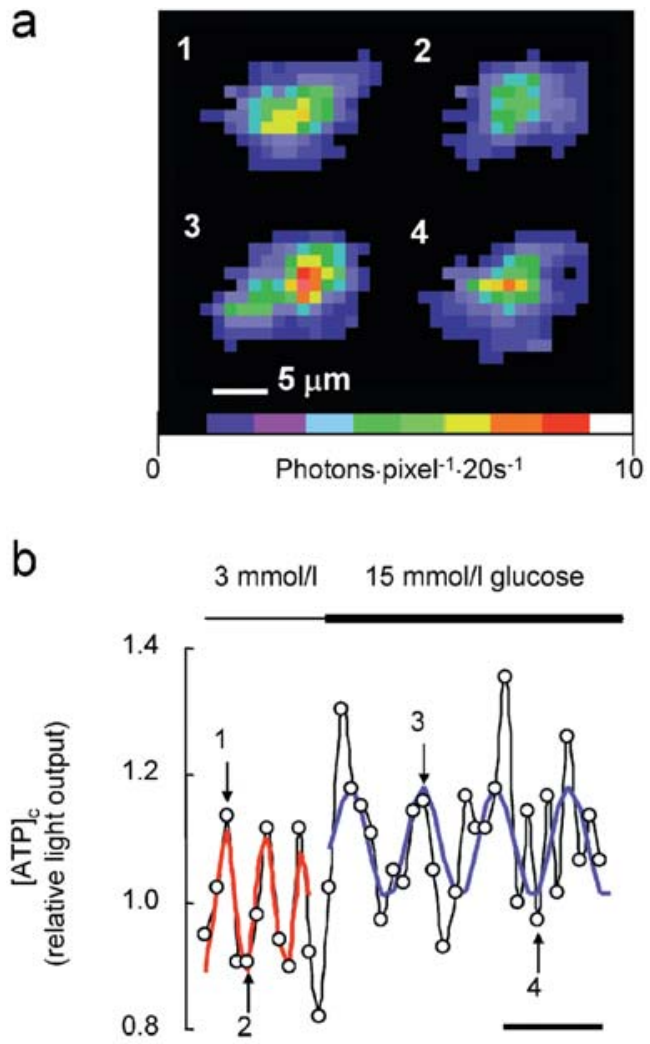

Fig. 1. Imaging ATP oscillations in a single living human beta cell. Human islets were infected, prior to photon-counting imaging of cellular bioluminescence, with an adenovirus expressing cytosolically targeted firefly luciferase, a reporter in free ATP concentration. Other details, see [38]. Images (a) were collected at the time points shown in (b). Horizontal bar: 2 min

\section{Glucose sensing: metabolic specialisation of the beta cell}

It is generally accepted that the intracellular metabolism of glucose and ATP synthesis, rather than the binding of the sugar to a specific "receptor", explains the triggering of insulin secretion (the "fuel hypothesis") $[24,25,26]$. The mammalian beta cell enjoys an unusual metabolic configuration, which tunes its glucose sensing to the insulin requirements of the whole animal. Firstly, glucose uptake is catalysed by the high $K_{\mathrm{m}}$ (i.e. low-affinity) liver-type glucose transporter, Glut2 [27]. Secondly, the first committed step in glycolysis, glucose phosphorylation, is catalysed in the beta cell by the low-affinity type IV hexokinase, better known as glucokinase (GK) [28]. Together, these "sensors" ensure that glucose phosphorylation increases sigmoidally as blood glucose concentrations rise over the physiological range $(3.5-8 \mathrm{mmol} / \mathrm{l})$. Correspondingly, inactivating mutations of GK in humans cause MODY2 [29], whilst beta-cell-specific inactivation of the $G K$ gene causes decreased sensitivity to glucose [30] and impaired insulin release in vivo [31].

Whilst the proximal aspects of glucose metabolism, catalysed by Glut 2 and Gk, are closely similar in the 
beta cell and liver (but different from the majority of cells), there are marked differences in the distal end of the glycolytic pathway in these two cell types. Firstly, beta cells express vanishingly low levels of lactate dehydrogenase (LDH) activity and of the plasma membrane monocarboxylate (lactate) transporter-1 (MCT1) $[32,33,34,35]$. These specialisations ensure that: (i) close to $100 \%$ of glucose-derived pyruvate enters the tricarboxylate/citrate (TCA) cycle and is either broken down to $\mathrm{H}_{2} \mathrm{O}$ and $\mathrm{CO}_{2}$ yielding ATP [32] $(75 \%)$, or assimilated into newly synthesised proteins [36]: this feature is important for the normal stimulation of insulin secretion by glucose since overexpression of LDH leads to a right shift in the dose response to the sugar [37, 38], and islet levels of LDH are increased in a model of type 2 diabetes, namely 85 to 95\% pancreatectomy [39]; (ii) circulating lactate and pyruvate do not stimulate insulin secretion during exercise [35] (Fig. 1a). Correspondingly, glucose-induced increases in [ATP] are significantly smaller in pancreatic alpha than beta cells [40] (unpublished observations, M. Ravier and G.A. Rutter), which possess relatively high levels of LDH. In contrast, levels of mitochondrial glycerolphosphate dehydrogenase are elevated in beta cells $[32,36,41]$, providing a mechanism for the re-oxidation of glycolytically derived $\mathrm{NADH}$ to $\mathrm{NAD}^{+}$.

Pyruvate enters mitochondrial metabolism in beta cells by one of two routes, oxidative decarboxylation by pyruvate dehydrogenase [42], or carboxylation to oxaloacetate catalysed by pyruvate carboxylase (PC) [43]. In contrast to the situation in the liver, where PC activity is required for gluconeogenesis, the absence of phosphoenolpyruvate carboxykinase and glucose 6-phosphatase means that this pathway is inactive in beta cells (Fig. 2). Instead, PC permits input of carbon atoms into the citrate cycle ("anaplerosis"), thus compensating for the subsequent "cataplerosis" (i.e. net loss of carbon atoms from the cycle), for example for amino acid biosynthesis [36]. Moreover, the generation by mitochondria of citrate and the production in the cytosol of NADPH by the action of malic enzyme may also be important for glucose signalling [44, 45], although presently the downstream mechanisms are unclear. On the other hand, by increasing cytosolic malonyl-CoA levels, glucose appears to inhibit the $\beta$-oxidation of fatty acids, and the consequent accumulation of acyl-CoA in the cytosol may enhance insulin release [46]. Finally, mitochondria provide a source of cytosolic glutamate [47], which is proposed to further enhance secretion $[48,49]$ perhaps by rendering the vesicle lumen more alkaline [50]. An action of glutamate on intravesicular glutamate receptors, thus generating local increases in the $\mathrm{Ca}^{2+}$-mobilising second messenger inositol 1,4,5-trisphosphate, has also been proposed very recently (F. Nicolleti, G.A. Rutter et al., unpublished results).

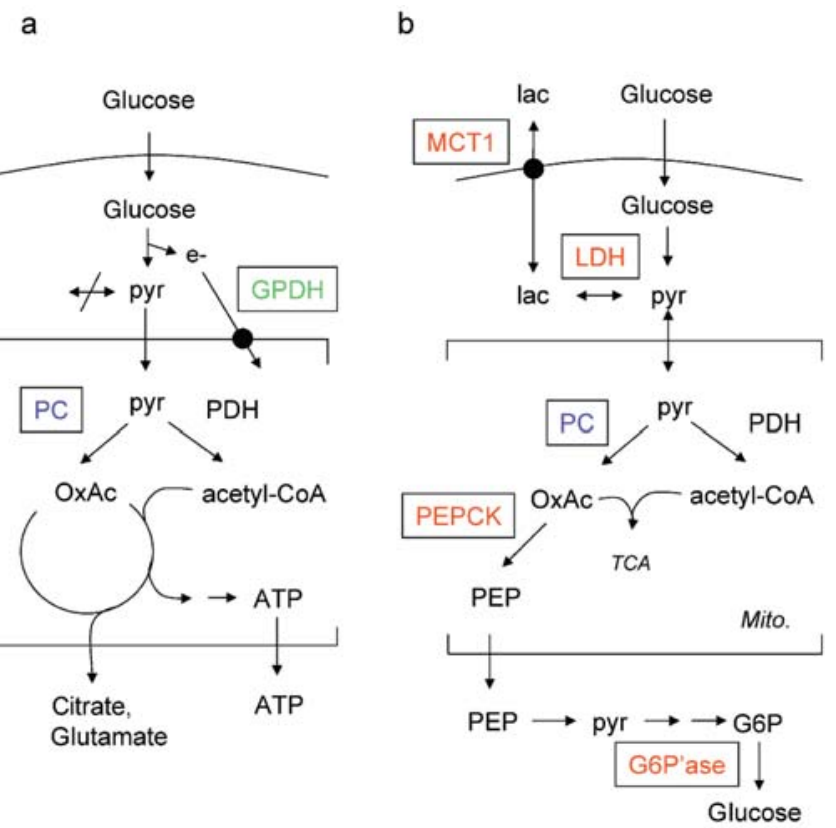

Fig. 2. Metabolic specialisations of (a) beta versus (b) liver cells. In both cell types pyruvate (pyr) derived from glucose can be oxidatively decarboxylated by pyruvate dehydrogenase (PDH) or carboxylated by pyruvate carboxylase (PC), furnishing oxaloacetate $(\mathrm{OxAc})$ for replenishment of carbon atoms (anaplerosis) in the citrate/tricarboxylate (TCA) cycle, and efficient generation of reducing equivalents for ATP synthesis by the respiratory chain. In the near-complete absence of lactate dehydrogenase (LDH) (b), electrons generated at the glyceraldehyde dehydrogenase step of glycolysis are fed into the mitochondrial respiratory chain when NADH is oxidised to $\mathrm{NAD}^{+}$ by mitochondrial glycerol phosphate dehydrogenase (GPDH), the levels of which are 60-fold higher than in the hepatocyte $[32,41]$. In the liver cells, high levels of the plasma membrane monocarboxylate transporter (MCT-1) and LDH permit conversion of exogenous lactate to pyruvate for subsequent gluconeogenesis, excluded in the beta cell by the absence of phosphoenolpyruvate carboxykinase (PEPCK) and glucose 6-phosphate dehydrogenase (G6P'ase)

\section{Alternative beta cell glucose sensors: AMP-activated protein kinase}

Recent findings from this $[51,52,53,54]$ and other laboratories $[55,56,57]$ have suggested that AMPactivated protein kinase (AMPK) may be a key regulator of insulin secretion.

Composed of $\alpha, \beta$, and $\gamma$ subunits, AMPK is a heterotrimeric enzyme complex [58], which is strongly stimulated by $5^{\prime} \mathrm{AMP}$, both allosterically and through the effects of an upstream protein kinase [59]. AMPK was first identified as an activity which, through the phosphorylation and inactivation of key biosynthetic enzymes [60], was responsible for rapidly shutting down fatty acid synthesis in the face of fuel depletion [58]. Subsequent cloning of the catalytic subunit of the enzyme [61] revealed that mammalian AMPK was a close homologue of the sucrose non-fermenting factor-1 complex in yeast and plants $[62,63]$. Multiple 
a

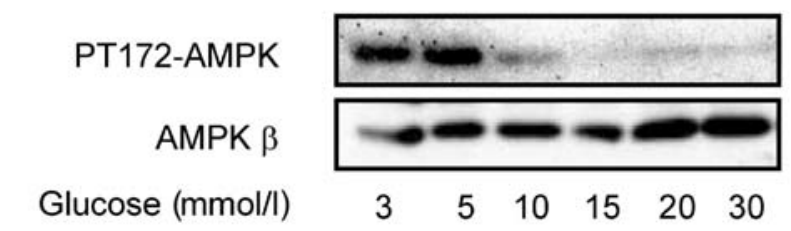

b

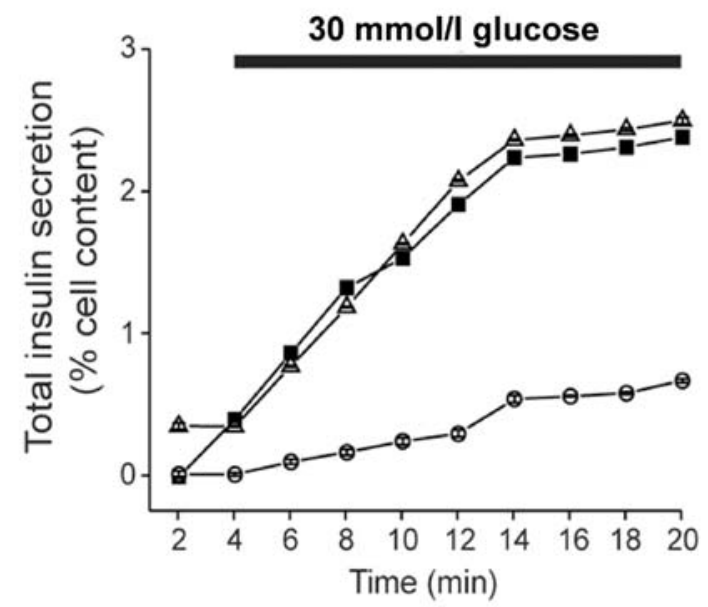

C

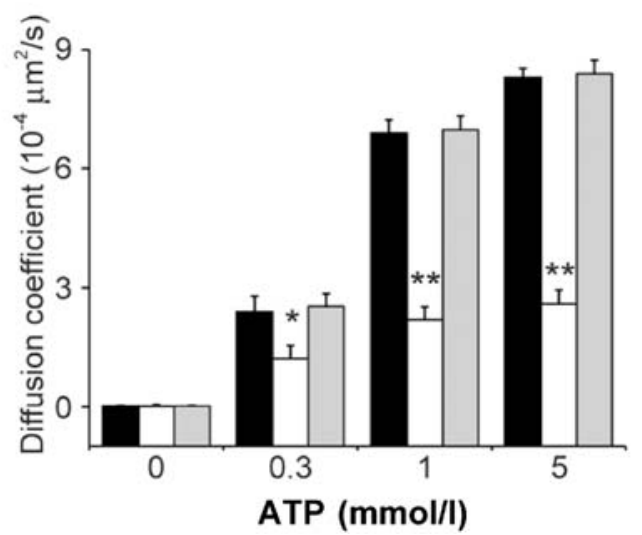

Fig. 3. Role of AMP-activated protein kinase in the control of insulin secretion. a. Changes in the phosphorylation state of AMPK $\alpha$-subunits at threonine-172 in response to alterations in glucose concentration. MIN6 cells were incubated for $1 \mathrm{~h}$ in modified Krebs-Ringer medium prior to cell lysis, SDS-polyacrylamide gel electrophoresis and western (immuno)blotting with anti-(phosphor-172) AMPK antibodies (Prof. D.G. Hardie, Department of Biochemistry, University of Dundee, Scotland). b. Impact of expressing dominant-negative (open triangles) or constitutively active (circles) forms of AMPK on insulin secretion from MIN6 cells. c. Impact of forced changes in AMPK activity on insulin secretory vesicle movement in permeabilised cells. Black bars: control (null) adenovirus; open bars: AMPK constitutively active; grey bars: AMPK dominant-negative. $* * p<0.01$ for the effect of AMPK constitutively active. Modified from [52] (a) and [53] (b, c)

isoforms of each AMPK subunit exist [64]. Islets and beta cells express $\alpha 1$ - and $\alpha 2$-containing AMPK complexes [51], both of which are acutely inhibited by elevated glucose concentrations in beta cell lines in-

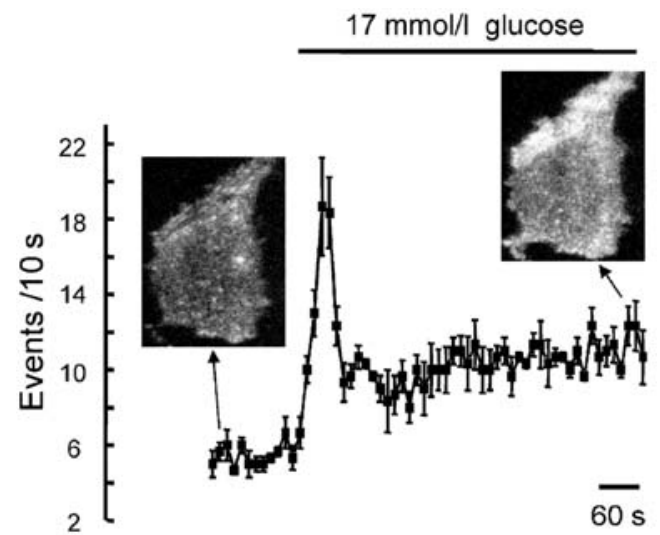

Fig. 4. Phases of insulin release imaged in single beta cells. MIN6 cells expressing the vesicle-anchored fluorescent probe phluorin [121] were imaged using TIRF microscopy initially at $3 \mathrm{mmol} / \mathrm{l}$ glucose and then at $17 \mathrm{mmol} / \mathrm{l}$ glucose as shown. Note the two distinct phases of the response to glucose

cluding HIT-T15 [55], MIN6 [51] and INS-1 [65], as well as in primary rodent and human islets [54] (Fig. 3a). Overexpression of a constitutively active form of AMPK leads to a near-complete suppression of glucose-stimulated insulin secretion (Fig. 3b) [52, 53] as also observed after the treatment of islets with the antidiabetic agent (and inhibitor of respiratory chain complex 1) metformin [54, 56]. Importantly, whilst high doses $(>200 \mu \mathrm{mol} / \mathrm{l})$ of the drug were required for rapid effects, physiological concentrations (20 $\mu \mathrm{mol} / \mathrm{l})$ were effective after longer incubation times $(16 \mathrm{~h})$. To a large part at least, the effects of activated AMPK can be attributed to a suppression of glucose oxidation $[52,56,57]$ and consequently $\mathrm{Ca}^{2+}$ influx. The mechanisms through which AMPK inhibits glucose metabolism have yet to be fully elucidated, but the activation of fatty acid oxidation and also a Randle effect [66] may be involved (though see [67] for a contrary view).

\section{Glucose-stimulated insulin secretion is biphasic: visualisation in living beta cells}

A cardinal feature of glucose-stimulated insulin secretion both in vitro and in vivo is its biphasic nature [68], which is evident both in isolated islets, and in single beta cells examined with vesicle-targeted fluorescent probes (Fig. 4). Until very recently, the mechanisms involved in biphasic insulin release were incompletely understood. Three theories have been proposed: (i) time-dependent changes in the concentration of signalling molecules [69]; (ii) physical recruitment of vesicles from a reserve to a readily releasable pool [70]; and (iii) recruitment of vesicles to a readily releasable pool by other mechanisms (e.g. covalent modification of a vesicle protein) [71]. Arguing against (i), increases in free [ATP] or intracellular 
$\mathrm{Ca}^{2+}$ concentration are usually monophasic or oscillatory [72]. As regards (ii) and (iii), electron microscopy showed that the morphologically docked pool comprised several hundred vesicles, a quantity significantly greater than the maximum number of vesicles in the readily releasable pool ( 15) [71], although only a tiny fraction of the total beta cell vesicle complement $(\sim 13,000)$. Nevertheless, recent data in neurones [73] suggest that readily releasable vesicles are not localised close to the presynaptic membrane, but are instead dispersed through the vesicle cluster. If this were the case in beta cells, then translocation would still be required even for vesicles in the readily releasable pool.

By labelling the secretory vesicle membrane with a chimeric construct encoding the membrane-resident protein phogrin (phosphatase on the granule of insulinoma, also called IA-2 $\beta$ [74]) fused to enhanced green fluorescent protein (EGFP), we aimed to image and quantify vesicle movement [75] in single living beta cells. Phogrin, a single transmembrane-spanning vesicle protein, is well suited to the task of localising EGFP to secretory granules, since it possesses multiple and partially redundant targeting sequences [76]. Fusion of EGFP to the C-terminus of phogrin also allows the photoprotein to face the cell cytosol, rather than the lumen, thus avoiding fluorescence quenching at low intraluminal $\mathrm{pH}$. In contrast, the fusion of insulin with EGFP [70] is more problematic [77], unless steps are taken to reduce expression levels (T. Tsuboi, G.A. Rutter, unpublished results). The use of a fluorescent marker combined with confocal microscopy $[75,78]$ provides advantages over the use of earlier microscopic techniques such as differential interference contrast $[79,80]$, since the latter may be complicated by interference from other organelles (e.g. mitochondria, lysosomes). In addition, "evanescent wave" microscopy (also called total internal reflection of fluorescence or TIRF microscopy) [53, 81, 82], in combination with fluorescent probes, allows selective analysis of fusion events at the cell surface (see below). Using the phogrin.EGFP chimera, it was possible to show that at low (sub-stimulatory) glucose concentrations vesicles displayed only short oscillatory ("jiggling") movements about a fixed point [75]. However, when the glucose concentration was raised, much longer (several $\mu \mathrm{m}$ ) vesicle excursions occurred, frequently towards the plasma membrane. Using TIRF microscopy, others [70] have recently suggested that first-phase secretion involves predocked vesicles, whilst sustained release involves "newcomers" to the membrane.

\section{Mechanisms involved in the regulation of vesicle recruitment to the plasma membrane}

Our early studies [75] showed that vesicle movement was sensitive to microtubule disruption with nocodazole, but barely affected by the disruption of actin filaments with colchicine. Moreover, simultaneous imaging of vesicles and microtubules suggested that the vast majority of long excursions occurred along microtubules [83]. Correspondingly, inhibition of vesicle recruitment to the cell surface through the expression of an inactivating (dominant-negative) mutant of kinesin lacking the motor domain [78] did not affect the initial phase of glucose-stimulated secretion in MIN6 cells (measured after $20 \mathrm{~min}$ ), but completely blocked further release of the hormone (measured at $90 \mathrm{~min}$ ). These findings demonstrate that whereas vesicle recruitment may not be the sole mechanism involved in the second phase of insulin secretion, it is an essential prerequisite for sustained release of the hormone. Interestingly, kinesin inhibition, achieved with either the dominant-negative mutant [78] or by RNA interference [83], led to an essentially complete cessation of vesicle movement, suggesting that anterograde movements of vesicles predominate in the beta cell.

Increases in ATP concentration activate kinesin-dependent vesicle movement in permeabilised cells [78] and may thus directly regulate the ATPase activity of kinesin by binding to the enzyme's active site. The loss of an inhibitory phosphorylation event, catalysed by AMPK [53], is another potential mechanism. Supporting the latter hypothesis, activation of endogenous AMPK or overexpression of the activated enzyme markedly decrease vesicle movements, not only in intact cells (where the effects are largely attributable to the suppression of glucose metabolism, see above) and in permeabilised cells where ATP concentration could be altered at will. In future it will be important to determine whether either of kinesin's subunits can be directly phosphorylated by AMPK (Fig. 3c). Another intriguing but untested possibility is whether inhibition of AMPK is involved in the second, sustained phase of glucose-stimulated insulin secretion, or in the "amplification" of insulin secretion by glucose when intracellular $\left[\mathrm{Ca}^{2+}\right]$ is clamped [72].

Recent data suggest that, whilst microfilaments probably play no role in mediating long-range movement of vesicles (see above), they are probably important as vesicles approach the cell surface. In beta, as in other neuroendocrine cells [84], the majority of cellular actin is located immediately beneath the plasma membrane under basal conditions, forming a "cortical actin network" that must be breached for vesicles to reach the plasmalemma [53, 85]. Correspondingly, stabilisation of the network with jasplakinolide causes a near complete inhibition of exocytosis, whilst its disruption with latrunculin B increases vesicle mobility and the number of release events [53]. Expression 
of a dominant-negative form of the actin-dependent motor myosin Va (myoVa), which is believed to be involved in the transport of vesicles in other systems [86], or its inactivation by RNA silencing (A. Varadi, G.A. Rutter, unpublished results), decreases the number of vesicles beneath the membrane and causes a profound inhibition of stimulated exocytosis. Similarly, antibodies against myosin light chain kinase inhibit insulin secretion in permeabilised cells [87]. Moreover, a small proportion of the cellular vesicle complement can be shown to be localised just beneath the plasma membrane (within $\sim 100 \mathrm{~nm}$ ) at low glucose concentrations and in apparent association with actin filaments (A. Varadi, G.A. Rutter, unpublished results). These interactions may play a dual role: (i) to deliver newly arrived vesicles to "holding" sites prior to release; (ii) to tether them prior to the arrival of a stimulatory signal (usually $\mathrm{Ca}^{2+}$ ). Interestingly, reversible interactions between melanosomes and myoVa have been demonstrated [88] and shown to be regulated by $\mathrm{Ca}^{2+}$-dependent phosphorylation mediated by calmodulin kinase II [45]. In beta cells, the $\mathrm{Ca}^{2+}$ trigger may lead to the dissociation of myoVa from its tethering site and the collapse of the actin network, thus liberating vesicles for fusion (Fig. 5). In addition to influx across the plasma membrane, $\mathrm{Ca}^{2+}$ released from the vesicle itself [89], as a result of the generation [90] of nicotinic acid adenine dinucleotide phosphate [91], may establish a local "microdomain" of high $\mathrm{Ca}^{2+}$ concentration [92] to activate both processes (Fig. 5a).

Might changes in vesicle motility or recruitment play a role in the pathology of type 2 diabetes? We $[93,94]$ and others $[95,96]$ have recently shown that elevations of beta cell triglyceride content caused by overexpression of the lipogenic transcription factor sterol regulatory element binding protein (SREBP1c) leads to a substantial accumulation of intracellular lipid and the near-complete elimination of both phases of glucose-stimulated insulin secretion from beta cells and islets, consistent with reports of inhibitory effects on insulin secretion of lipid infusion in vivo [97] and the culture of islets with fatty acids in vitro [98]. The effects of SREBP1c overexpression are associated with decreased glucose-induced increases in cytosolic [ATP], vesicle motility at both low and high glucose concentrations, and a reduction in the number of glucose-stimulated release events [99] (Fig. 5b). Whereas the effects of SREBP1c on glucose-stimulated vesicle excursions are probably due to the lowering of ATP concentrations in these conditions [94], the blockade of vesicle motility at low glucose concentrations, where there is no difference in ATP between control and SREBP-infected cells, may be due to the physical effects of numerous lipid droplets in the cell cytosol, as well as to changes in the expression of elements of the fusion machinery including Rim1 [100]. Interestingly, depolarisation-stimulated release is unaffected

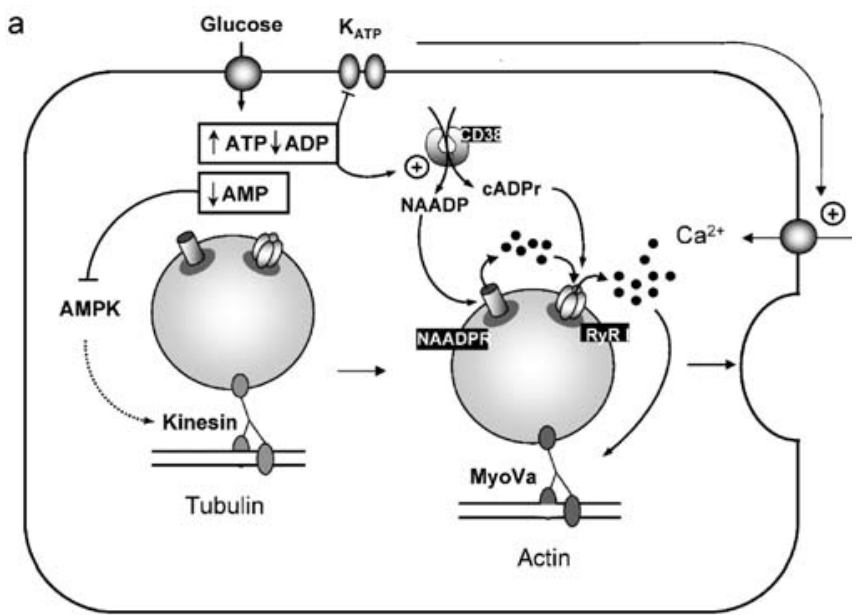

b

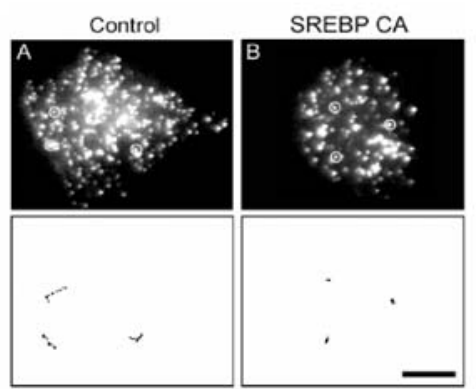

Fig. 5. Kiss and run or "cavicapture" exocytosis of vesicles. a. Vesicles close to the plasma membrane and initially tethered to the cortical actin network may be released during glucose stimulation as a result of $\mathrm{Ca}^{2+}$ influx and potentially of the mobilisation of $\mathrm{Ca}^{2+}$ held within the vesicle (cADPr, cyclicADPribose; CD38, cADPr synthase; RyR1, ryanodine receptor-1). Dephosphorylation of kinesin resulting from a fall in intracellular AMP concentration and a decrease in AMPK activity may lead to activated movement of vesicles more remote from the plasma membrane and their translocation towards site of exocytosis along microtubules. b. Vesicle movement, measured at $30 \mathrm{mmol} / \mathrm{l}$ glucose using confocal analysis of expressed phogrin.EGFP, is impeded in clonal beta cells overexpressing SREBP1c [99]. Tracks show the trajectories of three vesicles analysed at random. Scale bar: $5 \mu \mathrm{m}$

by SREBP1c overexpression, despite a decrease in the number of "morphologically docked" vesicles (i.e. those within $\sim 100 \mathrm{~nm}$ and so detectable within an evanescent field). This finding is consistent with the view that these short, $\mathrm{Ca}^{2+}{ }^{2}$ dependent final movements of the vesicle towards the plasma membrane are independent of microtubules/kinesin, but rely instead on myoVa/actin interactions.

\section{Mechanisms of vesicle release at the cell surface: full fusion or "kiss and run"?}

What is the fate of the secretory granule membrane once it finally arrives at the plasma membrane? It is generally accepted that the molecular machinery of 
a
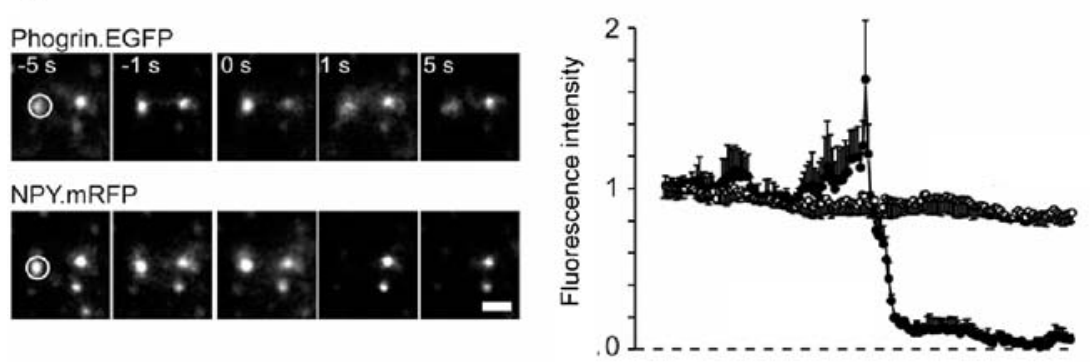

b
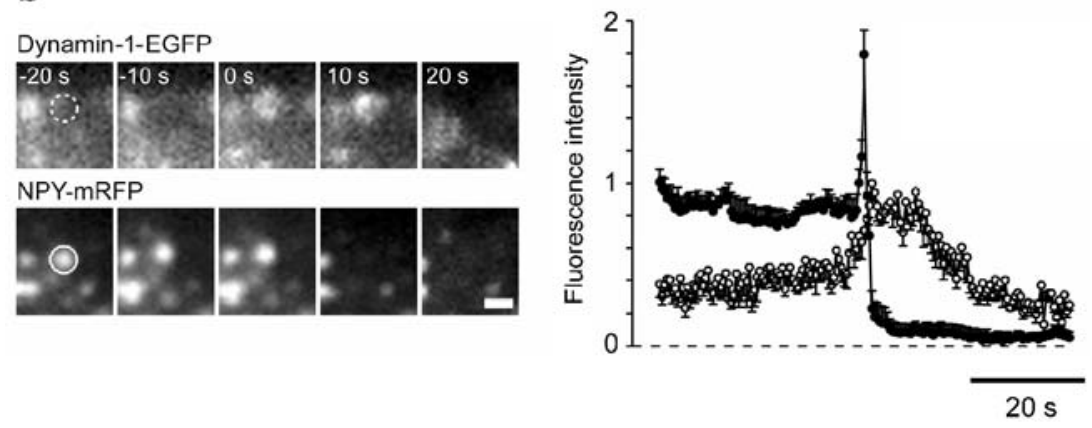

C

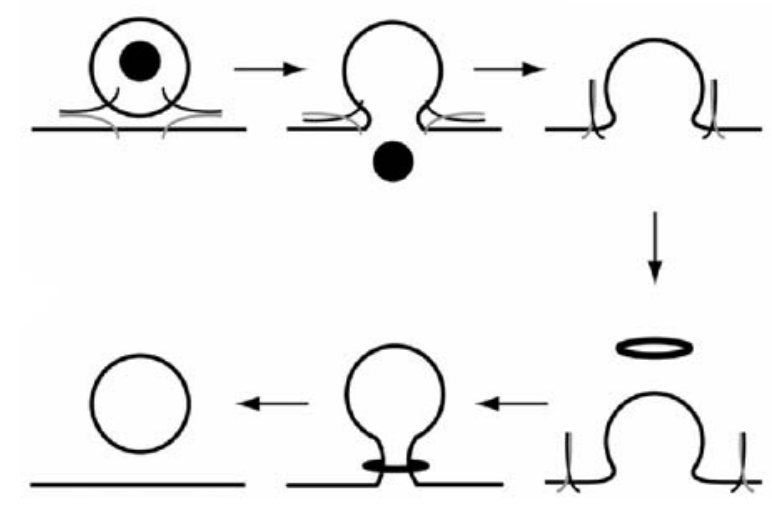

Fig. 6. Control of vesicle fusion. Five-sequential dual colour TIRF images showing the behaviour of the same individual vesicles bearing (a) phogrin.EGFP (time course: open circles) and NPY.mRFP (closed circles) or (b) dynamin-1 (open circles) plus NPY.mRFP (closed circles) after applying $50 \mathrm{mmol} / \mathrm{l} \mathrm{KCl}$ to the cell. The vesicle position before exocytosis is outlined by a circle. The scale bar represents $1 \mu \mathrm{m}$. The graphs (on right) show averaged fluorescence intensity traces (a: 36 events, 8 cells), (b: 34 events, 8 cells). Values are presented as the mean \pm SEM of the normalised fluorescence intensity. c. Model demonstrating the proposed role of dynamin- 1 in vesicle recapture. The closed circle represents insulin, and v- (black) and t(grey) N-ethyl-maleimide-sensitive fusion protein attachment receptors are shown initially tethering the vesicle and plasma membranes before catalysing the fusion of the two. Dynamin-1 is represented as an ellipse, which is recruited to the neck of the fusion pore to catalyse pore closure. Modified from [120]

vesicle fusion involves the interaction between soluble $\mathrm{N}$-ethyl-maleimide-sensitive fusion protein attachment receptors that are present on the vesicle and the plasma membrane [101], and such mechanisms appear to be operative in the beta cell [21].
For many years it was assumed that the release of insulin required the complete fusion of the secretory and plasma membranes, as was also believed to be the case during synaptic vesicle fusion [102]. Moreover, the detection by electron microscopy of the vesicle core apparently leaving the open mouth of a fused vesicle en masse suggested a complete-collapse model [103]. On the other hand, the uptake of relatively high molecular mass markers into dense core secretory vesicles has been reported both in insulin-secreting [104] and chromaffin cell-derived PC12 cells [105], suggesting that the fusion pore must subsequently close, recapturing extracellular material. As in the nerve terminal [106], it now seems likely that such transient events are predominant at physiological levels of stimulation, where the rate of exocytosis does not exceed the cell's capacity for endocytosis [107]. Indeed, when the fate of the insulin-containing vesicle is imaged simultaneously in living beta cells, using either the low-molecular-mass dye acridine orange [82] or the vesicle cargo protein neuropeptide Y (NPY) fused to monomeric red fluorescent protein (mRFP) or 
Venus [81] (where Venus is a highly fluorescent and relatively $\mathrm{pH}$-insensitive derivative or GFP) [108], genuine peptide release events occur without the concomitant release of the vesicle membrane protein phogrin.EGFP into the plasma membrane. This is perhaps the most compelling evidence that complete fusion of the vesicle membrane and the plasmalemma do not occur during insulin release. Very similar findings have also been made in PC12 cells [109], and suggest a conserved role for kiss-and-run or "cavicapture" exocytosis in neurosecretion.

By the combined use of a range of fluorescent reporters differing in molecular mass and targeted either to the vesicle membrane or lumen, it was possible to demonstrate the existence of multiple forms of cavicapture exocytosis, termed "transient", "mixed" and (quasi) "full" events [81]. The proportions of these varied according to the strength of cellular stimulation [81]. Transient events, which were detected as changes in vesicular $\mathrm{pH}$, probably involved the formation of a small $(\leq 2 \mathrm{~nm})$ fusion pore which is open for only a few seconds and allows the selective release of lowmolecular-mass molecules (e.g. ATP) [110]. "Mixed" events allow the release of selected vesicle membrane proteins (e.g. VAMP2) [81], with $\mathrm{K}_{\text {ATP }}$ channel subunits [111] possibly providing a mechanism for delivering proteins ultimately destined to function at the plasma membrane. Finally, (quasi) "full" events permit the release of soluble vesicle cargoes including NPY.Venus (which has approximately the same molecular dimensions as insulin), but do not permit the release of larger proteins such as tissue plasminogen activator (tPA, $70 \mathrm{M}_{\mathrm{r}}$ ) or phogrin (Fig. 6a). Importantly, this distinction between "full" but reversible events versus complete merger is difficult, if not impossible to detect, unless the fates of membrane and cargo markers are imaged simultaneously [81, 109]. This limitation may explain why recordings relying solely on soluble probes $[112,113]$ tend to invoke complete vesicle merger as the principal mechanism of insulin release.

\section{The fate of the transiently fused vesicle: nanomechanics of insulin vesicle recapture}

By what mechanisms is the recapture of the vesicle membrane achieved without full fusion? Dynamin is a $100 \mathrm{M}_{\mathrm{r}}$ GTP-driven mechanochemical enzyme related to mammalian mx-proteins, the yeast vps 1 gene product and Drosophila melanogaster shibire [114]. First identified as a microtubule-associated motor proteinlike activity [115], dynamin is implicated in the recapture of intact secretory vesicles in PC12 cells [105, 116]. Dynamin-1, the principal isoform in neuronal and neuroendocrine cells, possesses GTPase, pleckstrin homology and C-terminal proline-rich domains, and is proposed to act either as a mechanochemical enzyme that cleaves the neck of an endocytosing vesicle ("pinchase") [117], or as a molecular spring ("poppase") that extends and eventually ruptures the tubule linking the vesicle and donor membrane [118]. Dynamin-1 is required for "rapid endocytosis" detectable by capacitance measurements after mild (physiological) stimulation of chromaffin cells [119]. Imaged by TIRF microscopy, dynamin-1.EGFP is recruited, in the absence of other components of the classical endocytic pathway (e.g. clathrin and epsin), to sites of NPY.Venus release in MIN6 beta cells (Fig. 6b). Furthermore, overexpression of mutant dynamin-1 bearing a defective pleckstrin homology domain permits the release of large peptide cargoes including phogrin.EGFP and tPA [120]. Together, these findings indicate that dynamin-1 plays a key role in the endocytic mechanism by which the semi-fused secretory vesicle is recovered from the plasma membrane, essentially intact, following cargo release.

\section{Conclusions}

Imaging techniques have provided previously unsuspected information on the complex molecular machinery of insulin release, and demonstrated new layers of regulation. By identifying the important role of particular gene products (kinesin, myoVa, dynamin etc.), these approaches provide potential new therapeutic targets, as well as identifying potentially new diabetes genes that may be useful predictors of this disease.

Acknowledgements. Research in the author's laboratory is supported by grants from the Wellcome Trust (Programme Grant 067081), the Juvenile Diabetes Research Fund International, the Biotechnology and Biological Sciences Research Council and Diabetes UK. G.A. Rutter is a Research Leave Fellow of the Wellcome Trust. I thank Drs Takashi Tsuboi, Aniko Varadi, Gabriela daSilvaXavier, Laura Parton and Isabelle Leclerc for useful discussion.

\section{References}

1. Butler AE, Janson J, Bonner-Weir S, Ritzel R, Rizza RA, Butler PC (2003) Beta-cell deficit and increased beta-cell apoptosis in humans with type 2 diabetes. Diabetes 52:102-110

2. Foulis AK, Stewart JA (1984) The pancreas in recent-onset type 1 (insulin-dependent) diabetes mellitus: insulin content of islets, insulitis and associated changes in the exocrine acinar tissue. Diabetologia 26:456-461

3. McCulloch DK, Koerker DJ, Kahn SE, Bonner-Weir S, Palmer JP (1991) Correlations of in vivo beta-cell function tests with beta-cell mass and pancreatic insulin content in streptozocin-administered baboons. Diabetes 40:673-679

4. Cotes PM, Mussett MV, Berryman I et al. (1969) Collaborative study of estimates by radioimmunoassay of insulin concentrations in plasma samples examined in groups of five or six laboratories. J Endocrinol 45:557-569

5. Huang L, Shen H, Atkinson MA, Kennedy RT (1995) Detection of exocytosis at individual pancreatic beta cells by 
amperometry at a chemically modified microelectrode. Proc Natl Acad Sci USA 92:9608-9612

6. Lehr S, Herbst M, Kampermann J, Greger R, Ullrich S (1997) Adrenaline inhibits depolarization-induced increases in capacitance in the presence of elevated $(\mathrm{Ca} 2+)(\mathrm{i})$ in insulin secreting cells. FEBS Lett 415:1-5

7. Rorsman P (1997) The pancreatic beta-cell as a fuel sensor: an electrophysiologist's viewpoint. Diabetologia 40:487-495

8. Rutter GA, Leclerc I, Tsuboi T, Xavier GS, Diraison F, Qian Q (2004) Imaging glucose-regulated insulin secretion and gene expression in single islet beta-cells: control by AMPactivated protein kinase. Cell Biochem Biophys 40:179-190

9. Detimary P, Gilon P, Henquin JC (1998) Interplay between cytoplasmic $\mathrm{Ca}^{2+}$ and the ATP/ADP ratio: a feedback control mechanism in mouse pancreatic islets. Biochem $\mathrm{J}$ 333:269-274

10. Kennedy HJ, Pouli AE, Jouaville LS, Rizzuto R, Rutter GA (1999) Glucose-induced ATP microdomains in single islet beta-cells. J Biol Chem 274:13281-13291

11. Ainscow EK, Rutter GA (2001) Mitochondrial priming modifies $\mathrm{Ca}^{2+}$ oscillations and insulin secretion in pancreatic islets. Biochem J 353:175-180

12. Cook DL, Hales CN (1984) Intracellular ATP directly blocks $\mathrm{K}^{+}$channels in pancreatic B-cells. Nature 311:271-273

13. Ashcroft FM, Harrison DE, Ashcroft SJH (1984) Glucose induces closure of single potassium channels in isolated rat pancreatic B-cells. Nature 312:446-448

14. Inagaki N, Gonoi T, Clement JP IV et al. (1995) Reconstitution of I(KATP): An inward rectifier subunit plus the sulfonylurea receptor. Science 270:1166-1170

15. AguilarBryan L, Nichols CG, Wechsler SW et al. (1995) Cloning of the beta cell high-affinity sulfonylurea receptor: a regulator of insulin secretion. Science 268:423-426

16. Boschero AC, Tombaccini D, Atwater I (1988) Effects of glucose on insulin release and $86 \mathrm{Rb}$ permeability in cultured neonatal and adult rat islets. FEBS Lett 236:375-379

17. Henquin JC, Meissner HP (1984) Significance of ionic fluxes and changes in membrane potential for stimulus-secretion coupling in pancreatic B-cells. Experientia 40: 1043-1052

18. Safayhi H, Haase H, Kramer U et al. (1997) L-type calcium channels in insulin-secreting cells: biochemical characterization and phosphorylation in RINm5F cells. Mol Endocrinol 11:619-629

19. Grapengiesser E, Gylfe E, Hellman B (1989) Glucose effects on cytoplasmic $\mathrm{Ca}^{2+}$ of individual pancreatic betacells recorded by two procedures for dual-wavelength fluorometry. Exp Clin Endocrinol 93:321-327

20. Theler J-M, Mollard P, Guérineau N et al. (1992) Video imaging of cytosolic $\mathrm{Ca}^{2+}$ in pancreatic beta-cells stimulated by glucose, carbachol, and ATP. J Biol Chem 267:18110-18117

21. Lang JC (1999) Molecular mechanisms and regulation of insulin exocytosis as a paradigm of endocrine secretion. Eur J Biochem 259:3-17

22. Rorsman P, Eliasson L, Renstrom E, Gromada J, Barg S, Gopel S (2000) The cell physiology of biphasic insulin secretion. News Physiol Sci 15:72-77

23. Rutter GA, Theler J-M, Murta M, Wollheim CB, Pozzan T, Rizzuto R (1993) Stimulated $\mathrm{Ca}^{2+}$ influx raises mitochondrial free $\mathrm{Ca}^{2+}$ to supramicromolar levels in a pancreatic beta-cell line: possible role in glucose and agonist-induced insulin secretion. J Biol Chem 268:22385-22390

24. Coore HG, Randle PJ (1964) Inhibition of glucose phosphorylation by mannoheptulose. Biochem J 91:56-59

25. Hedeskov CJ (1980) Mechanisms of glucose-induced insulin secretion. Physiol Rev 60:442-509
26. Meglasson MD, Matschinsky FM (1986) Pancreatic islet glucose metabolism and regulation of insulin secretion. Diabetes Metab Rev 2:163-214

27. Thorens B, Sarkar HK, Kaback HR, Lodish HF (1988) Cloning and functional expression in bacteria of a novel glucose transporter present in liver intestine kidney and B-pancreatic islet cells. Cell 55:281-290

28. Iynedjian PB (1993) Mammalian glucokinase and its gene. Biochem J 293:1-13

29. Velho G, Blanche H, Vaxillaire M et al. (1997) Identification of 14 new glucokinase mutations and description of the clinical profile of 42 MODY-2 families. Diabetologia 40:217-224

30. Aizawa T, Asanuma N, Terauchi Y et al. (1996) Analysis of the pancreatic beta cell in the mouse with targeted disruption of the pancreatic beta cell-specific glucokinase gene. Biochem Biophys Res Commun 229:460-465

31. Efrat S, Leiser M, Wu YJ et al. (1994) Ribozyme-mediated attenuation of pancreatic beta-cell glucokinase expression in transgenic mice results in impaired glucose-induced insulin secretion. Proc Natl Acad Sci USA 91:2051-2055

32. Sekine N, Cirulli V, Regazzi R et al. (1994) Low lactate dehydrogenase and high mitochondrial glycerol phosphate dehydrogenase in pancreatic beta-cell. Potential role in nutrient sensing. J Biol Chem 269:4895-4902

33. Liang Y, Bai G, Doliba N et al. (1996) Glucose metabolism and insulin release in mouse betaHC9 cells, as model for wild-type pancreatic beta-cells. Am J Physiol 270:E846-E857

34. Zhao C, Wilson CM, Schuit F, Halestrap AP, Rutter GA (2001) Expression and distribution of lactate / monocarboxylate transporter (MCT) isoforms in pancreatic islets and the exocrine pancreas. Diabetes 50:361-366

35. Ishihara H, Wang H, Drewes LR, Wollheim CB (1999) Overexpression of monocarboxylate transporter and lactate dehydrogenase alters insulin secretory responses to pyruvate and lactate in beta cells. J Clin Invest 104:1621-1629

36. Schuit F, DeVos A, Farfari S et al. (1997) Metabolic fate of glucose in purified islet cells-glucose-regulated anaplerosis in beta cells. J Biol Chem 272:18572-18579

37. Zhao C, Rutter GA (1998) Overexpression of lactate dehydrogenase A attenuates glucose-induced insulin secretion in stable MIN-6 beta-cell lines. FEBS Lett 430:213-216

38. Ainscow EK, Zhao C, Rutter GA (2000) Acute overexpression of lactate dehydrogenase-A perturbs beta-cell mitochondrial metabolism and insulin secretion. Diabetes 49:1149-1155

39. Jonas JC, Sharma A, Hasenkamp W et al. (1999) Chronic hyperglycemia triggers loss of pancreatic beta cell differentiation in an animal model of diabetes. J Biol Chem 274:14112-14121

40. Ishihara H, Maechler P, Gjinovci A, Herrera PL, Wollheim CB (2003) Islet beta-cell secretion determines glucagon release from neighbouring alpha-cells. Nat Cell Biol 5:330-335

41. MacDonald MJ (1981) High content of mitochondrial glycerol-3-phosphate dehydrogenase in pancreatic islets and its inhibition by diazoxide. J Biol Chem 256:8287-8290

42. McCormack JG, Longo EA, Corkey BE (1990) Glucoseinduced activation of pyruvate dehydrogenase in isolated rat pancreatic islets. Biochem J 267:527-530

43. MacDonald MJ (1993) Glucose enters mitochondrial metabolism via both carboxylation and decarboxylation of pyruvate in pancreatic islets. Metabolism 42:1229-1231

44. Farfari S, Schulz V, Corkey B, Prentki M (2000) Glucoseregulated anaplerosis and cataplerosis in pancreatic betacells-possible implication of a pyruvate/citrate shuttle in insulin secretion. Diabetes 49:718-726 
45. Karcher RL, Roland JT, Zappacosta F et al. (2001) Cell cycle regulation of myosin-V by calcium/calmodulin-dependent protein kinase II. Science 293:1317-1320

46. Prentki M, Vischer S, Glennon MC, Regazzi R, Deeney JT, Corkey BE (1992) Malonyl-CoA and long chain acyl-CoA esters as metabolic coupling factors in nutrient-induced insulin secretion. J Biol Chem 267:5802-5810

47. Maechler P, Wollheim CB (1999) Mitochondrial glutamate acts as a messenger in glucose-induced insulin exocytosis. Nature 402:685-689

48. Hoy M, Maechler P, Efanov AM, Wollheim CB, Berggren PO, Gromada J (2002) Increase in cellular glutamate levels stimulates exocytosis in pancreatic beta-cells. FEBS Lett 531:199-203

49. Bertrand G, Ishiyama N, Nenquin M, Ravier MA, Henquin JC (2002) The elevation of glutamate content and the amplification of insulin secretion in glucose-stimulated pancreatic islets are not causally related. J Biol Chem 277:32883-32891

50. Eto K, Yamashita T, Hirose K et al. (2003) Glucose metabolism and glutamate analog acutely alkalinize $\mathrm{pH}$ of insulin secretory vesicles of pancreatic beta-cells. Am J Physiol Endocrinol Metab 285:E262-E271

51. Da Silva Xavier G, Leclerc I, Salt IP et al. (2000) Role of AMP-activated protein kinase in the regulation by glucose of islet beta-cell gene expression. Proc Natl Acad Sci USA 97:4023-4028

52. Da Silva Xavier G, Leclerc I, Varadi A, Tsuboi T, Moule SK, Rutter GA (2003) Role for AMP-activated protein kinase in glucose-stimulated insulin secretion and preproinsulin gene expression. Biochem J 371:761-774

53. Tsuboi T, Silva Xavier G da, Leclerc I, Rutter GA (2003) 5' AMP-activated protein kinase controls insulin-containing secretory vesicle dynamics. J Biol Chem 278:52042-52051

54. Leclerc I, Woltersdorf WW, Silva Xavier G da et al. (2004) Metformin, but not leptin, regulates AMP-activated protein kinase in pancreatic islets: impact on glucose-stimulated insulin secretion. Am J Physiol Endocrinol Metab 286: E1023-E1031

55. Salt IP, Johnson G, Ashcroft SJ, Hardie DG (1998) AMPactivated protein kinase is activated by low glucose in cell lines derived from pancreatic beta cells, and may regulate insulin release. Biochem J 335:533-539

56. Kefas BA, Cai Y, Kerckhofs K et al. (2004). Metformin-induced stimulation of AMP-activated protein kinase in betacells impairs their glucose-responsiveness and can lead to apoptosis. Biochem Pharmacol 68:409-416

57. Eto K, Yamashita T, Matsui J, Terauchi Y, Noda M, Kadowaki T (2002) Genetic manipulations of fatty acid metabolism in beta-cells are associated with dysregulated insulin secretion. Diabetes 51 [Suppl 3]:S414-S420

58. Hardie DG, Carling D, Carlson M (1998) The AMP-activated/SNF1 protein kinase subfamily: metabolic sensors of the eukaryotic cell? Annu Rev Biochem 67:821-855

59. Carling D (2004) The AMP-activated protein kinase cascade-a unifying system for energy control. Trends Biochem Sci 29:18-24

60. Carling D, Zammit VA, Hardie DG (1987) A common bicyclic protein kinase cascade inactivates the regulatory enzymes of fatty acid and cholesterol biosynthesis. FEBS Lett 223:217-222

61. Beri RK, Marley AE, See CG et al. (1994) Molecular cloning, expression and chromosomal localisation of human AMP-activated protein kinase. FEBS Lett 356:117-121

62. Carlson M (1999) Glucose repression in yeast. Curr Opin Microbiol 2:202-207

63. Rutter GA, Tavaré JM, Palmer DG (2000) Regulation of gene expression by glucose. N Physiol Sci 15:149-154
64. Kemp BE, Mitchelhill KI, Stapleton D, Michell BJ, Chen ZP, Witters LA (1999) Dealing with energy demand: the AMPactivated protein kinase. Trends Biochem Sci 24:22-25

65. Leclerc I, da Silva Xavier G, Rutter GA (2002) AMP- and stress-activated protein kinases: key regulators of gene transcription in mammalian cells. Prog Nucl Acid Res Mol Biol 71:69-90

66. Zhou YP, Grill VE (1994) Long-term exposure of rat pancreatic islets to fatty acids inhibits glucose-induced insulin secretion and biosynthesis through a glucose fatty acid cycle. J Clin Invest 93:870-876

67. Segall L, Lameloise N, Assimacopoulos Jeannet F et al. (1999) Lipid rather than glucose metabolism is implicated in altered insulin secretion caused by oleate in INS-1 cells. Am J Physiol Endocrinol Metab 40:E521-E528

68. Curry DL, Bennett LL, Grodsky GM (1968) Dynamics of insulin secretion by the perfused rat pancreas. Endocrinology 83:572-584

69. Nesher R, Cerasi E (1987) Biphasic insulin release as the expression of combined inhibitory and potentiating effects of glucose. Endocrinology 121:1017-1024

70. Ohara-Imaizumi M, Nishiwaki C, Kikuta T, Nagai S, Nakamichi Y, Nagamatsu S (2004) TIRF imaging of docking and fusion of single insulin granule motion in primary rat pancreatic beta-cells: different behaviour of granule motion between normal and Goto-Kakizaki diabetic rat beta-cells. Biochem J 381:13-18

71. Barg S, Olofsson CS, Schriever-Abeln J et al. (2002) Delay between fusion pore opening and peptide release from large dense-core vesicles in neuroendocrine cells. Neuron 33:287-299

72. Henquin JC (2000) Triggering and amplifying pathways of regulation of insulin secretion by glucose. Diabetes 49 : $1751-1760$

73. Rizzoli SO, Betz WJ (2004) The structural organization of the readily releasable pool of synaptic vesicles. Science 303:2037-2039

74. Wasmeier C, Hutton JC (1996) Molecular cloning of phogrin, a protein-tyrosine phosphatase homologue localized to insulin secretory granule membranes. J Biol Chem 271:18161-18170

75. Pouli AE, Emmanouilidou E, Zhao C, Wasmeier C, Hutton JC, Rutter GA (1998) Secretory granule dynamics visualised in vivo with a phogrin-green fluorescent protein chimaera. Biochem J 333:193-199

76. Wasmeier C, Bright NA, Hutton JC (2002) The lumenal domain of the integral membrane protein phogrin mediates targeting to secretory granules. Traffic 3:654-665

77. Pouli AE, Kennedy HJ, Schofield JG, Rutter GA (1998) Insulin targeting to the regulated secretory pathway after fusion with green fluorescent protein and firefly luciferase. Biochem J 331:669-675

78. Varadi A, Ainscow EK, Allan VJ, Rutter GA (2002) Involvement of conventional kinesin in glucose-stimulated secretory-granule movements and exocytosis in clonal pancreatic beta-cells. J Cell Sci 115:4177-4189

79. Ishihara Y, Sakurai T, Habara Y, Busik JV, Kanno T, Terakawa S (2000) Exocytosis in the dissociated pancreatic acinar cells of the guinea pig directly visualized by VECDIC microscopy. Biochem Biophys Res Commun 277: 134-137

80. Sakurai T, Terakawa S (1995) Insulin secretion from pancreatic beta cells directly visualised as exocytosis by video microscopy. Bio Images 3:85-92

81. Tsuboi T, Rutter GA (2003) Multiple forms of kiss and run exocytosis revealed by evanescent wave microscopy. Curr Biol 13:563-567 
82. Tsuboi T, Zhao C, Terakawa S, Rutter GA (2000) Simultaneous evanescent wave imaging of insulin vesicle membrane and cargo during a single exocytotic event. Curr Biol 10:1307-1310

83. Varadi A, Tsuboi T, Johnson-Cadwell LI, Allan VJ, Rutter GA (2003) Kinesin I and cytoplasmic dynein orchestrate glucose-stimulated insulin-containing vesicle movements in clonal MIN6 beta-cells. Biochem Biophys Res Commun 311:272-282

84. Vitale ML, Seward EP, Trifaro JM (1995) Chromaffin cell cortical actin network dynamics control the size of the release-ready vesicle pool and the initial rate of exocytosis. Neuron 14:353-363

85. Thurmond DC, Gonelle-Gispert C, Furukawa M, Halban PA, Pessin JE (2003) Glucose-stimulated insulin secretion is coupled to the interaction of actin with the t-SNARE (target membrane soluble $\mathrm{N}$-ethylmaleimide-sensitive factor attachment protein receptor protein) complex. Mol Endocrinol 17:732-742

86. Langford GM (2002) Myosin-V, a versatile motor for short-range vesicle transport. Traffic 3:859-865

87. Iida Y, Senda T, Matsukawa Y et al. (1997) Myosin lightchain phosphorylation controls insulin secretion at a proximal step in the secretory cascade. Am J Physiol Endocrinol Met 36:E782-E789

88. Rogers SL, Karcher RL, Roland JT, Minin AA, Steffen W, Gelfand VI (1999) Regulation of melanosome movement in the cell cycle by reversible association with myosin V. J Cell Biol 146:1265-1276

89. Mitchell K, Pinton P, Varadi A et al. (2001) Dense core secretory vesicles revealed as a dynamic $\mathrm{Ca}^{2+}$ store in neuroendocrine cells with a VAMP2.aequorin chimaera. J Cell Biol 155:41-51

90. Masgrau R, Churchill GC, Morgan AJ, Ashcroft SJ, Galione A (2003) NAADP. A new second messenger for glucose-induced $\mathrm{Ca}^{2+}$ responses in clonal pancreatic beta cells. Curr Biol 13:247-251

91. Mitchell KJ, Lai FA, Rutter GA (2003) Ryanodine receptor type I and nicotinic acid adenine dinucleotide phosphate (NAADP) receptors mediate $\mathrm{Ca}^{2+}$ release from insulin-containing vesicles in living pancreatic beta-cells (MIN6). J Biol Chem 278:11057-11064

92. Emmanouilidou E, Teschemacher A, Pouli AE, Nicholls LI, Seward EP, Rutter GA (1999) Imaging $\left(\mathrm{Ca}^{2+}\right)$ changes at the secretory vesicle surface with a recombinant targeted chameleon. Curr Biol 9:915-918

93. Andreolas C, Silva Xavier G da, Diraison F et al. (2002) Stimulation of acetyl-CoA carboxylase gene expression by glucose requires insulin release and sterol regulatory element binding protein 1c in MIN6 beta cells. Diabetes 51:2536-2545

94. Diraison F, Parton L, Ferre P et al. (2004) Over-expression of sterol-regulatory-element-binding protein-1c (SREBP1c) in rat pancreatic islets induces lipogenesis and decreases glucose-stimulated insulin release: modulation by 5aminoimidazole-4-carboxamide ribonucleoside (AICAR). Biochem J 378:769-778

95. Wang H, Maechler P, Antinozzi PA et al. (2003) The transcription factor SREBP-1c is instrumental in the development of beta-cell dysfunction. J Biol Chem 278: 16622-16629

96. Yamashita T, Eto K, Okazaki Y et al. (2004) Role of uncoupling protein-2 up-regulation and triglyceride accumulation in impaired glucose-stimulated insulin secretion in a beta-cell lipotoxicity model overexpressing sterol regulatory element-binding protein-1c. Endocrinology 145: 3566-3577
97. Sako Y, Grill VE (1990) A 48-hour lipid infusion in the rat time-dependently inhibits glucose-induced insulin secretion and $\mathrm{B}$ cell oxidation through a process likely coupled to fatty acid oxidation. Endocrinology 127: 1580-1589

98. Zhou YP, Grill VE (1994) Long-term exposure of rat pancreatic islets to fatty acids inhibits glucose-induced insulin secretion and biosynthesis through a glucose fatty acid cycle. J Clin Invest 93:870-876

99. Parton L, Smith ER, Diraison F, Tsuboi T, Rutter GA (2004) Impact of sterol response element binding protein1c on insulin-containing secretory vesicle dynamics. Diabetologia (in press)

100. Diraison F, Leclerc I, Motakis E, Parton L, Rutter GA (2004) Impact of sterol response element binding protein1c and AMP-activated protein kinase on pancreatic islet beta-cell gene expression profile. Diabetes (in press)

101. Sudhof TC (2000) The synaptic vesicle cycle revisited. Neuron 28:317-320

102. Heuser JE, Reese TS (1973) Evidence for recycling of synaptic vesicle membrane during transmitter release at the frog neuromuscular junction. J Cell Biol 57:315-344

103. Orci L, Amherdt M, Malaisse Lagae F, Rouiller C, Renold AE (1973) Insulin release by emiocytosis: demonstration with freeze-etching technique. Science 179:82-84

104. Sawano F, Ravazzola M, Amherdt M, Perrelet A, Orci L (1986) Horseradish peroxidase uptake and crinophagy in insulin-secreting cells. Exp Cell Res 164:174-182

105. Holroyd P, Lang T, Wenzel D, Camilli P de, Jahn R (2002) Imaging direct, dynamin-dependent recapture of fusing secretory granules on plasma membrane lawns from PC12 cells. Proc Natl Acad Sci USA 99:16806-16811

106. Ceccarelli B, Hurlbut WP, Mauro A (1973) Turnover of transmitter and synaptic vesicles at the frog neuromuscular junction. J Cell Biol 57:499-524

107. Palfrey HC, Artalejo CR (2003) Secretion: kiss and run caught on film. Curr Biol 13:R397-R399

108. Nagai T, Ibata K, Park ES, Kubota M, Mikoshiba K, Miyawaki A (2002) A variant of yellow fluorescent protein with fast and efficient maturation for cell-biological applications. Nat Biotechnol 20:87-90

109. Taraska JW, Perrais D, Ohara-Imaizumi M, Nagamatsu S, Almers W (2003) Secretory granules are recaptured largely intact after stimulated exocytosis in cultured endocrine cells. Proc Natl Acad Sci USA 100:2070-2075

110. Hellman B, Dansk H, Grapengiesser E (2004) Pancreatic beta-cells communicate via intermittent release of ATP. Am J Physiol Endocrinol Metab 286:E759-E765

111. Geng X, Li L, Watkins S, Robbins PD, Drain P (2003) The insulin secretory granule is the major site of K(ATP) channels of the endocrine pancreas. Diabetes 52:767-776

112. Ma L, Bindokas VP, Kuznetsov A et al. (2004) Direct imaging shows that insulin granule exocytosis occurs by complete vesicle fusion. Proc Natl Acad Sci USA 101:9266-9271

113. Takahashi N, Kishimoto T, Nemoto T, Kadowaki T, Kasai $\mathrm{H}$ (2002) Fusion pore dynamics and insulin granule exocytosis in the pancreatic islet. Science 297:1349-1352

114. Van der Bliek AM, Meyerowitz EM (1991) Dynamin-like protein encoded by the Drosophila shibire gene associated with vesicular traffic. Nature 351:411-414

115. Vallee RB, Shpetner HS (1990) Motor proteins of cytoplasmic microtubules. Annu Rev Biochem 59:909-932

116. Graham ME, O'Callaghan DW, McMahon HT, Burgoyne RD (2002) Dynamin-dependent and dynamin-independent processes contribute to the regulation of single vesicle release kinetics and quantal size. Proc Natl Acad Sci USA 99:7124-7129 
117. Hinshaw JE (2000) Dynamin and its role in membrane fission. Annu Rev Cell Dev Biol 16:483-519

118. Praefcke GJ, McMahon HT (2004) The dynamin superfamily: universal membrane tubulation and fission molecules? Nat Rev Mol Cell Biol 5:133-147

119. Artalejo CR, Elhamdani A, Palfrey HC (2002) Sustained stimulation shifts the mechanism of endocytosis from dynamin-1-dependent rapid endocytosis to clathrin- and dynamin-2-mediated slow endocytosis in chromaffin cells. Proc Natl Acad Sci USA 99:6358-6363

120. Tsuboi T, McMahon H, Rutter GA (2004) Mechanisms of dense core vesicle recapture following "kiss and run" ("cavicapture") exocytosis in insulin-secreting cells. J Biol Chem. Epub Aug 25 (ahead of print)

121. Miesenbock G, De Angelis DA, Rothman JE (1998) Visualizing secretion and synaptic transmission with $\mathrm{pH}$-sensitive green fluorescent proteins. Nature 394:192-195 